\title{
Changes in Fungicide Resistance Frequency and Population Structure of Pyricularia oryzae after Discontinuance of MBI-D Fungicides
} F. Suzuki, National Agricultural Research Center for Kyushu Okinawa Region, 2421 Suya, Koshi, Kumamoto 861-
1192, Japan; J. Yamaguchi, Saga Agricultural Experiment Research Center, Kawazoe Saga 840-2205, Japan; and A. Koba, T. Nakajima, and M. Arai, National Agricultural Research Center for Kyushu Okinawa Region, 2421 Suya, Koshi, Kumamoto 861-1192, Japan

\begin{abstract}
Suzuki, F., Yamaguchi, J., Koba, A., Nakajima, T., and Arai, M. 2010. Changes in fungicide resistance frequency and population structure of Pyricularia oryzae after discontinuance of MBI-D fungicides. Plant Dis. 94:329-334.

The changes in fungicide resistance frequency and population structure of the rice blast fungus Pyricularia oryzae were monitored after the discontinuance of melanin biosynthesis inhibitor targeting scytalone dehydratase (MBI-D) fungicides use in Saga Prefecture, Japan. After discontinuance in 2003, the frequency of resistant isolates decreased from $71.8 \%$ in 2002 to $25 \%$ in 2003, and became undetectable in 2007. The initial marked decrease was due to a decline of isolates possessing the predominant haplotype, although the haplotypic diversity among resistant isolates remained high from 2003 to 2005. These results revealed that resistant isolates were less fit in comparison with sensitive isolates in the absence of MBI-D fungicide pressure under field conditions. Pairwise $\mathrm{F}_{\mathrm{ST}}$ values indicated that the change in population structure after MBI-D discontinuance was explainable by a rapid change in the proportions of resistant and sensitive subpopulations. Depending upon the existence of fitness cost and rapid changes in population structure, it may be possible to reintroduce MBI-D fungicides in areas where resistance has already developed, although we speculate that fitness cost related to MBI-D resistance may be small based on our present results and previous findings.
\end{abstract}

Pyricularia oryzae (teleomorph: Magnaporthe oryzae [2]) causes rice blast, the most damaging disease of rice. Management of rice blast has relied on treatment with fungicides, because resistant cultivars become vulnerable within a few years after release. In Japan, melanin biosynthesis inhibitor targeting scytalone dehydratase (MBI-D) fungicides were introduced in 1998 as efficient and specific fungicides for control of rice blast. MBI-D is a tightly binding competitive inhibitor of scytalone dehydratase (SDH), a key enzyme in the biosynthesis of melanin. These fungicides, including carpropamid, diclocymet, and fenoxanil, are registered mainly as granule-type fungicide-insecticide mixtures for nursery box treatment. The use of MBI-D fungicides spread quickly because nursery box treatment has numerous advantages including long-term effectiveness, reduced application frequency and quantity, and shorter working hours.

However, failure of MBI-D to control rice blast was reported in Saga Prefecture, Kyushu, in 2001, and the occurrence of

Corresponding author: F. Suzuki

E-mail: fsuzuk@affrc.go.jp

Accepted for publication 11 November 2009.

doi:10.1094/PDIS-94-3-0329

(C) 2010 The American Phytopathological Society isolates resistant to MBI-D was confirmed there (34). Resistance of P. oryzae to MBI$\mathrm{D}$ was associated with a single point mutation of the SDH gene that resulted in the replacement of valine by methionine at amino acid position 75 (V75M) (30). In the crystal structure of the SDHcarpropamid complex, V75 is located at the tip of the C-helix of SDH and forms the mouth part of the active pocket (19). Because methionine has a larger side chain than valine, this conversion seems to reduce the binding affinity of MBI-D fungicide molecules for an active pocket of mutant SDH (33), whereas mutant SDH still retains a significant level of the enzymatic activity and allows infection of a host plant $(30,33)$. Other mutations conferring resistance to MBI-D fungicides have not been reported so far, except for V75M of SDH. MBI-D-resistant strains soon spread throughout most of Kyushu during 2002-2003 (24,28), and were subsequently reported from many other prefectures $(7,23)$. Population structure analysis based on Pot 2 repetitive element polymerase chain reaction (rep-PCR) fingerprint data revealed that the resistant isolates possessed high genetic diversity, indicating that the resistance occurred in a multi-genetic background (28). In that study, three predominant haplotypes were largely responsible for the rapid and widespread development of resistance in Kyushu. The most predominant haplo- type, designated $\mathrm{Sa} 4$, was widespread in Saga.

The use of MBI-D fungicides was discontinued in Saga in 2003 as an immediate countermeasure against the development of resistance. According to Saga prefectural government statistics, the use decreased from a peak of over $20 \%$ of rice plantings in 2001 to almost $0 \%$ in 2003 (Fig. 1). In place of MBI-D, other types of melanin biosynthesis inhibitors targeting polyhydroxynaphthalene reductase (MBI$\mathrm{R}$ fungicides) and plant defense activators increased in use after 2003, restoring the use of MBI-R fungicides to the level that existed before MBI-D fungicides were released in 1998. Switching among these fungicides in Saga would have impacted on the population structure of rice blast fungi. By assessing the influence of MBID discontinuance in Saga, we hoped to reveal the fitness of MBI-D-resistant strains under practical conditions.

Understanding the fitness of MBI-Dresistant strains would have significant benefits for rice blast management. If there is a fitness cost associated with MBI-D resistance, then the frequency of resistant strains would decline in the absence of fungicide pressure. This would allow the reintroduction of MBI-D fungicides into areas where resistant strains are less fit than sensitive wild-type strains. However, there are certain problems in estimating the fitness of $P$. oryzae. First, it is difficult to know what parameters should be selected for the measurement of fitness. In many studies with other fungicides, fitness was estimated by measuring spore formation, growth rate, pathogenicity, or survival under severe conditions in the laboratory $(1,6,10,12,22)$, but it is unclear whether these parameters correlate with the fitness of MBI-D resistance. Some studies demonstrated that MBI-D-resistant and -sensitive $P$. oryzae isolates had no difference in several parameters such as growth rate, temperature sensitivity, UV tolerance, and pathogenicity $(13,26)$. Furthermore, genetic instability resulting from mutations can occur spontaneously in $P$. oryzae during laboratory subculture. It is known that several mutations associated with melanin production, spore morphology, and host specificity can occur at apparently higher frequency (16,31). Therefore, the differences observed between resistant and sen- 
sitive isolates may be due to differences in the genetic backgrounds of the isolates rather than to fitness costs associated with resistance alleles.

We think that more useful information on fitness can be obtained by population analyses under field conditions if large populations and many field isolates can be monitored over the long term. Through the case in Saga, we had the opportunity to investigate temporal changes in resistance frequency and population structure of $P$.

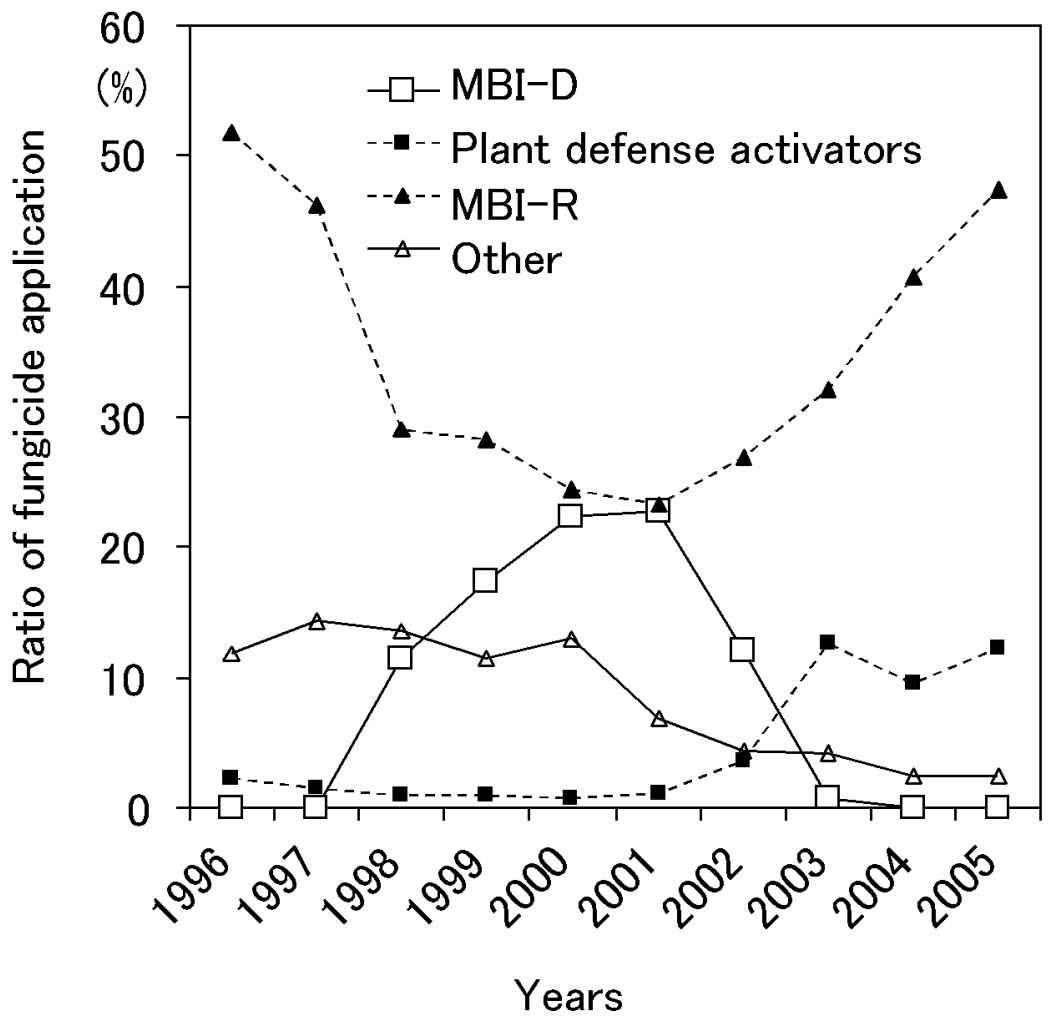

Fig. 1. Changes in fungicide types used for nursery box treatment in Saga Prefecture between 1996 and 2005. Open squares, melanin biosynthesis inhibitor targeting scytalone dehydratase (MBI-D) fungicides; solid squares, plant defense activators; solid triangles, MBI-R fungicides; open triangles, other types of fungicides. MBI-D fungicides were introduced in 1998 and discontinued in 2003 because of development of resistance in Pyricularia oryzae. Ratios of fungicide use relate to rice cultivation area $(\sim 29,000 \mathrm{ha})$ based on statistics from the Saga prefectural government. oryzae after the use of MBI-D fungicides had been discontinued. The objectives of the present study were (i) to monitor the frequency of resistance in $P$. oryzae populations collected from Saga after the discontinuance of MBI-D fungicides, (ii) to analyze population structure dynamics using the Pot 2 rep-PCR technique and pairwise $F_{S T}$ values, and (iii) to estimate the fitness of resistant isolates by combining the data from those analyses. It was anticipated that the results would be useful for assessing the possibility of reintroducing MBI-D fungicides in rotation, or in combination, in areas where resistance has already developed.

\section{MATERIALS AND METHODS}

Sample collection. A total of 2,148 single-spore isolates of $P$. oryzae were collected from paddy fields across Saga Prefecture during 2002 to 2007 (Table 1). In 2002 , rice leaves infected with blast were sampled in locations where MBI-D fungicides were widely applied. From 2003 to 2007, both leaves and panicles were collected, leaves in July-August and panicles in September-October. The collections were divided into 11 temporal populations based on sampling year and blast type (Table 1). Among them, two populations of leaf blast collected in 2002 and 2003, consisting of 690 isolates, were the same as reported in a previous study (28). In principle, up to five plants with characteristic blast symptoms were sampled randomly in each paddy field. Samples with necrotic lesions were washed in tap water for 1 to 3 min and placed on moist filter paper in petri dishes for $24 \mathrm{~h}$ at $25^{\circ} \mathrm{C}$ to induce sporulation. Conidia were dislodged from individual sporulating lesions onto potato

Table 1. Analysis of temporal populations of Pyricularia oryzae in Saga Prefecture by Pot2 repetitive element polymerase chain reaction (rep-PCR) and melanin biosynthesis inhibitor targeting scytalone dehydratase (MBI-D) fungicides resistance

\begin{tabular}{|c|c|c|c|c|c|c|}
\hline Sampling year & Origin of isolates $^{a}$ & $\begin{array}{c}\text { No. of } \\
\text { sampling sites }^{b}\end{array}$ & No. of isolates ${ }^{c}$ & No. of haplotypes ${ }^{d}$ & $\begin{array}{l}\text { No. of unique } \\
\text { haplotypes }^{\mathrm{e}}\end{array}$ & $\begin{array}{c}\text { Haplotypic } \\
\text { diversity }^{\mathrm{f}}\end{array}$ \\
\hline \multirow[t]{2}{*}{2002} & $\mathrm{~L}$ & $102(75)$ & $404(290)$ & $37(15)$ & $7(5)$ & $0.76(0.55)$ \\
\hline & Total & $102(75)$ & 404 (290) & $37(15)$ & $7(5)$ & $0.76(0.55)$ \\
\hline \multirow[t]{3}{*}{2003} & $\mathrm{~L}$ & $64(46)$ & $286(158)$ & $35(18)$ & $10(5)$ & $0.88(0.80)$ \\
\hline & $\mathrm{P}$ & $40(16)$ & $172(43)$ & $24(8)$ & $5(1)$ & $0.92(0.87)$ \\
\hline & Total & $104(62)$ & $458(201)$ & $44(19)$ & $16(6)$ & $0.91(0.81)$ \\
\hline \multirow[t]{3}{*}{2004} & $\mathrm{~L}$ & $79(31)$ & $420(104)$ & $46(11)$ & $12(1)$ & $0.90(0.72)$ \\
\hline & $\mathrm{P}$ & $38(14)$ & $187(33)$ & $28(9)$ & $8(2)$ & $0.91(0.86)$ \\
\hline & Total & $117(45)$ & 607 (137) & $55(15)$ & $21(3)$ & $0.90(0.74)$ \\
\hline \multirow[t]{3}{*}{2005} & $\mathrm{~L}$ & $31(11)$ & $130(26)$ & $24(8)$ & $4(0)$ & $0.82(0.85)$ \\
\hline & $\mathrm{P}$ & $15(4)$ & 77 (9) & $15(4)$ & $1(0)$ & $0.77(0.62)$ \\
\hline & Total & $46(15)$ & 207 (35) & $28(9)$ & $5(0)$ & $0.81(0.86)$ \\
\hline \multirow{3}{*}{2006} & $\mathrm{~L}$ & $36(2)$ & $109(2)$ & $14(2)$ & $2(0)$ & $0.65(0.50)$ \\
\hline & $\mathrm{P}$ & $33(2)$ & $161(7)$ & $12(1)$ & $0(0)$ & $0.54(0.00)$ \\
\hline & Total & $69(4)$ & $270(9)$ & $16(2)$ & $2(0)$ & $0.59(0.20)$ \\
\hline \multirow{3}{*}{2007} & $\mathrm{~L}$ & $22(4)$ & $75(7)$ & $13(1)$ & $1(0)$ & $0.60(0.00)$ \\
\hline & $\mathrm{P}$ & $27(0)$ & $129(0)$ & $17(0)$ & $5(0)$ & $0.73(0.00)$ \\
\hline & Total & 49 (4) & $204(7)$ & $21(1)$ & $5(0)$ & $0.69(0.00)$ \\
\hline 2002-2007 total & & 487 (205) & $2,148(679)$ & $105(29)$ & $56(14)$ & $0.88(0.73)$ \\
\hline
\end{tabular}

a Populations of Pyricularia oryzae were collected from leaves (L) or panicles (P).

${ }^{b}$ Number of sampling sites based on total isolates of each population (based on resistant isolates).

${ }^{\mathrm{c}}$ Number of total isolates obtained from each population (resistant isolates).

${ }^{\mathrm{d}}$ Number of haplotypes observed among total isolates of each population (among resistant isolates).

${ }^{\mathrm{e}}$ Number of unique haplotypes observed in only one population based on total isolates of each population (based on resistant isolates).

${ }^{\mathrm{f}}$ Haplotypic diversity was determined (14) from total isolates data of each population (resistant isolates data). 
dextrose agar (PDA) plates. Monoconidial isolates were picked aseptically and transferred to fresh PDA plates. Filter paper disks were placed on the PDA plates, and the mycelium was allowed to grow over the disks. After the fungus had completely colonized them, the disks were removed from the culture plate and air-dried. The disks were then placed in sterilized vials and stored at $-20^{\circ} \mathrm{C}$.

DNA isolation and diagnosis of MBID resistance. $P$. oryzae isolates were grown in petri dishes on potato dextrose broth (Difco Laboratories, Detroit, MI) at $25^{\circ} \mathrm{C}$ for 4 to 5 days. Mycelia were transferred to a microcentrifuge tube, and total genomic DNA of the isolates was extracted with an Ultra Clean microbial DNA isolation kit (Mo Bio Laboratories Inc., Carlsbad, CA).

Gene diagnosis of MBI-D resistance was based on primer-introduced restriction enzyme analysis (PIRA) PCR with the primer pair SCDH4 (5'-TTATTTGTCGCC AAAGGTCTCC-3') and SCDH13 (5'-TTC GTCGGCATGGTCTCGAGCATCTAG-3'), as described (9). PCR was performed in a total volume of $20 \mu \mathrm{l}$ containing $1 \times$ reaction buffer $\left(\mathrm{Mg}^{2+}\right.$ plus; Takara Bio Inc., Shiga, Japan), $200 \mu \mathrm{M}$ each dNTP, $0.5 \mu \mathrm{M}$ each primer, 10 ng genomic DNA, and 0.4 units of Takara Taq DNA polymerase (Takara Bio). Cycling conditions were $94^{\circ} \mathrm{C}$ for 10 min; 30 cycles of $94^{\circ} \mathrm{C}$ for $1 \mathrm{~min}, 50^{\circ} \mathrm{C}$ for $1 \mathrm{~min}$, and $72^{\circ} \mathrm{C}$ for $2 \mathrm{~min}$; and a final extension of $5 \mathrm{~min}$ at $72^{\circ} \mathrm{C}$. The PCR product $(2 \mu \mathrm{l})$ was digested with $X b a \mathrm{I}$, and the restriction fragments were resolved by electrophoresis in 3\% agarose gels (SeaPlaque GTG agarose, FMC Bio Products, Rockland, ME).

Pot2 rep-PCR. Rep-PCR fingerprints were generated as described $(27,28)$. The primer Pot2-TIR (5'-ACAGGGGGTACG CAACGTTA-3') was designed from the terminal inverted repeat sequence of Pot 2 (8). PCR reactions were carried out in 20 $\mu \mathrm{l}$ containing $10 \mathrm{ng}$ genomic DNA, $0.5 \mu \mathrm{M}$ Pot2-TIR, $400 \mu \mathrm{M}$ each dNTP, $1 \times$ ExTaq buffer, $2 \mathrm{mM} \mathrm{MgCl}_{2}$, and 1 unit of ExTaq DNA polymerase (Takara Bio). PCR amplifications were performed in an iCycler (Bio-Rad, Hercules, CA) for an initial 2 min at $94^{\circ} \mathrm{C} ; 35$ cycles of $1 \mathrm{~min}$ at $94^{\circ} \mathrm{C}, 1$ min at $62^{\circ} \mathrm{C}$, and $6 \mathrm{~min}$ at $72^{\circ} \mathrm{C}$; a final extension for $15 \mathrm{~min}$ at $72^{\circ} \mathrm{C}$; and holding at $4^{\circ} \mathrm{C}$. The PCR products were separated by electrophoresis in $1 \%$ agarose gels (SeaKem GTG agarose, BioWhittaker Products, Rockland, ME) in 1× Tris-borate buffer ( $89 \mathrm{mM}$ Tris, $89 \mathrm{mM}$ boric acid, 2 mM EDTA). Gels were run for $1.5 \mathrm{~h}$ at 100 $\mathrm{V}$ and stained with ethidium bromide. Polymorphic rep-PCR bands ranging from 0.2 to $6 \mathrm{~kb}$ in length were scored manually. The presence or absence of bands in each isolate was converted into binary data (1 for presence and 0 for absence). We scored presence or absence at 49 loci generated from Pot 2 rep-PCR.
Data analysis. Haplotypic diversity within populations was evaluated by using Nei's unbiased diversity index (20), $H$, calculated as $H=n /(n-1) \times\left(1-\sum_{i} p_{i}{ }^{2}\right)$, where $p$ is the relative frequency of the $i$ th haplotype and $n$ is the sample size within a population. The index of genetic difference $\left(\mathrm{F}_{\mathrm{ST}}\right)$ between populations by pairwise difference (32) was estimated with the ARLEQUIN software package (L. Excoffier, University of Geneva). Correlation between $\mathrm{F}_{\mathrm{ST}}$ values and time-course among populations was analyzed in Microsoft Excel.

\section{RESULTS}

Frequency of MBI-D resistance after discontinuance of MBI-D fungicides. The frequency of MBI-D-resistant isolates of leaf blast in Saga was $71.8 \%(73.5 \%$ based on number of fields) in 2002, when MBI-D fungicides were applied to approximately $12 \%$ of the rice crop (Table 1 , Figs. 1 and 2). Government statistics on fungicide application to nursery boxes indicated a peak usage of MBI-D fungicides in over $20 \%$ of the rice crop in 2001. The use of MBI-R fungicides and plant defense activators increased from 2003 in place of MBI-D fungicides (Fig. 1). As soon as the MBI-D fungicides were discontinued, the frequency of resistant isolates obtained from infected panicle tissue began to decrease sharply, reaching $25 \%$ (40\% based on number of fields) in 2003 (Fig. 2). The frequency decreased slowly in 2004 and 2005, decreased to an extremely low level in 2006, and finally became undetectable in 2007. The frequency of resistant isolates tended to decrease faster in panicle blast populations than in leaf blast populations between 2003 and 2005 (Fig. 2). Populations during 2005 and 2007 consisted of a relatively small number of isolates, because rice blast developed at a very low frequency in these years, compared to the populations during 2002 and 2004. Nevertheless, the sample sizes of all populations were still sufficient to allow meaningful statistical analyses according to the general standard (17).

Fingerprint analysis by rep-PCR. Using rep-PCR with the single primer Pot2TIR, we identified 105 different haplotypes among the 2,148 isolates. Rep-PCR amplified 7 to 14 bands per isolates, ranging in size from 0.2 to $6.0 \mathrm{~kb}$ (Table 1). The 679 resistant isolates were separable into 29 distinct haplotypes, 12 of which were common with those of sensitive isolates. The frequency of haplotypes unique to a year ranged from $13 \%(2 / 16)$ in 2004 to $38 \%(21 / 55)$ in 2006, and averaged $25 \%$. Diversities of total and resistant isolates in each temporal population were calculated from haplotype data (Fig. 2, Table 1). Total isolates possessed relatively high haplotypic diversities between 2002 and $2005(\mathrm{H}=$ 0.76 to 0.92 ), and slightly lower diversities in 2006 and 2007 ( $\mathrm{H}=0.54$ to 0.73 ). Resistant isolates similarly possessed relatively high haplotypic diversities between 2003 and $2005(\mathrm{H}=0.62$ to 0.87$)$.

The predominant haplotype among resistant isolates, designated Sa4, in 189 leaf blast isolates $(46.8 \%)$ was detected from 54 sites (52.9\%) in 2002 throughout Saga (28). The discontinuance of MBI-D fungicides was reflected directly in the frequency of Sa4: 22\% (leaf blast) and 6\% (panicle blast) in 2003, and 0\% in 2006 (Fig. 3). The rapid decrease in the frequency of resistant isolates between 2002 and 2006 can be explained by the decline of Sa4. Other haplotypes detected among resistant isolates were maintained until 2007 (leaf blast). On the other hand, among haplotypes of sensitive isolates, Sa5 increased and became predominant after 2005 (Fig. 3).

Temporal dynamics of population structure after discontinuance of MBI-D

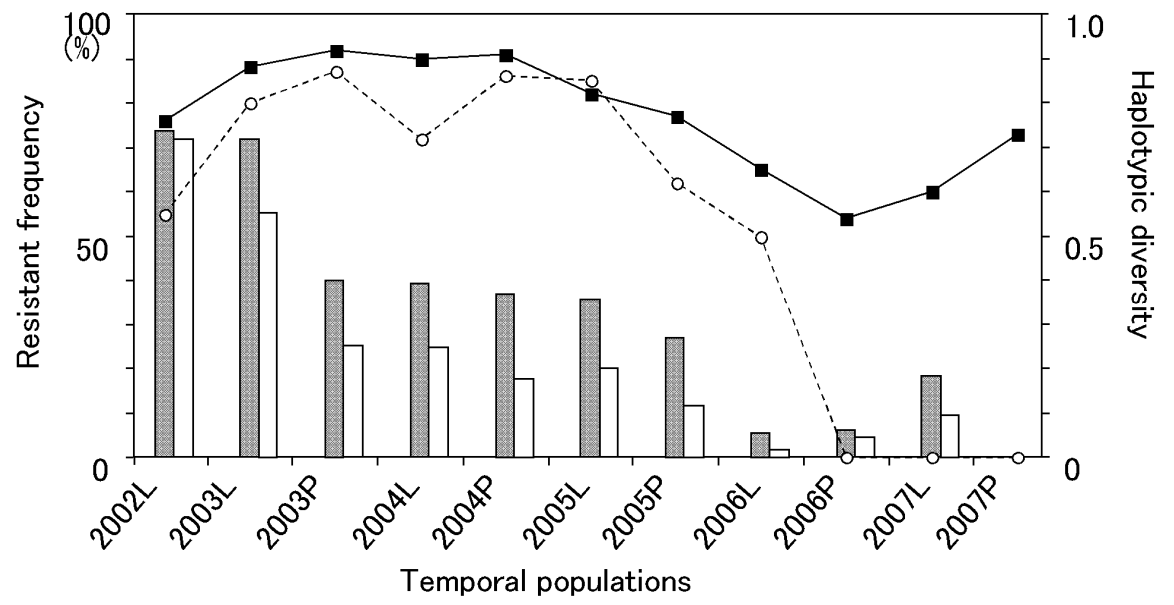

Fig. 2. Changes in frequencies of resistance and haplotypic diversity of Pyricularia oryzae populations collected in Saga Prefecture between 2002 and 2007. Frequencies of resistance are based on numbers of fields (shaded bars) and numbers of isolates (open bars); haplotypic diversities are calculated among total isolates (solid squares) and among melanin biosynthesis inhibitor targeting scytalone dehydratase (MBI-D)-resistant isolates (open circles). MBI-D fungicides application was discontinued in 2003. 
fungicides. The matrix of population pairwise $F_{S T}$ values (indicating genetic distance) suggested temporal differences among populations of total isolates (Table 2 below diagonal). All values of $\mathrm{F}_{\mathrm{ST}}(0.065$ to 0.405 ) were significant in the comparison of the 2002-L population with the other 10 populations. There was a significant positive correlation between $\mathrm{F}_{\mathrm{ST}}$ and time $\left(R^{2}=0.83, P=0.0003\right)$ among the total leaf blast population (Fig. 4). The same comparison of subpopulations of sensitive isolates revealed only small differences in $\mathrm{F}_{\mathrm{ST}}$ values (0.020 to 0.103 ; Table 2 above diagonal), indicating a weak correlation between $\mathrm{F}_{\mathrm{ST}}$ and time $\left(R^{2}=\right.$ $0.38, P=0.06$ ). Thus, the sensitive subpopulations were stable over the latter 6 years, although they increased rapidly in size relative to the resistant subpopulations after discontinuance of the MBI-D fungicides.

\section{DISCUSSION}

Long-term monitoring of MBI-D resistance in $P$. oryzae populations showed that it decreased to an undetectable level over 5 years after the discontinuance of MBI-D fungicides. The effect of the migration of rice blast fungus from other prefectures through seed transmission on the decrease of resistance would have been small during the study period, because rice seeds were circulated only within Saga Prefecture, in line with the agricultural policy of the prefectural government. This decline of resistance frequency provides evidence that MBI-D resistance is not stable in the absence of selection pressure, and that resistant isolates do not appear to have fitness that is equal to that of sensitive isolates. Monitoring after the discontinuance of organophosphorous fungicides and kasugamycin, to which resistance in $P$. oryzae emerged in paddy fields in the 1970 s in Japan $(11,18)$, also showed that resistance decreased rapidly $(4,5)$. These cases show that the build-up of resistance is at least partially reversible when the selection pressure of the fungicides is removed or minimized. The development of rice blast during 2005 and 2007 was at a very low frequency compared to populations during 2002 and 2004. This decline in disease incidence might have been due to unfavorable weather conditions for the rice blast pathogen and the influence of

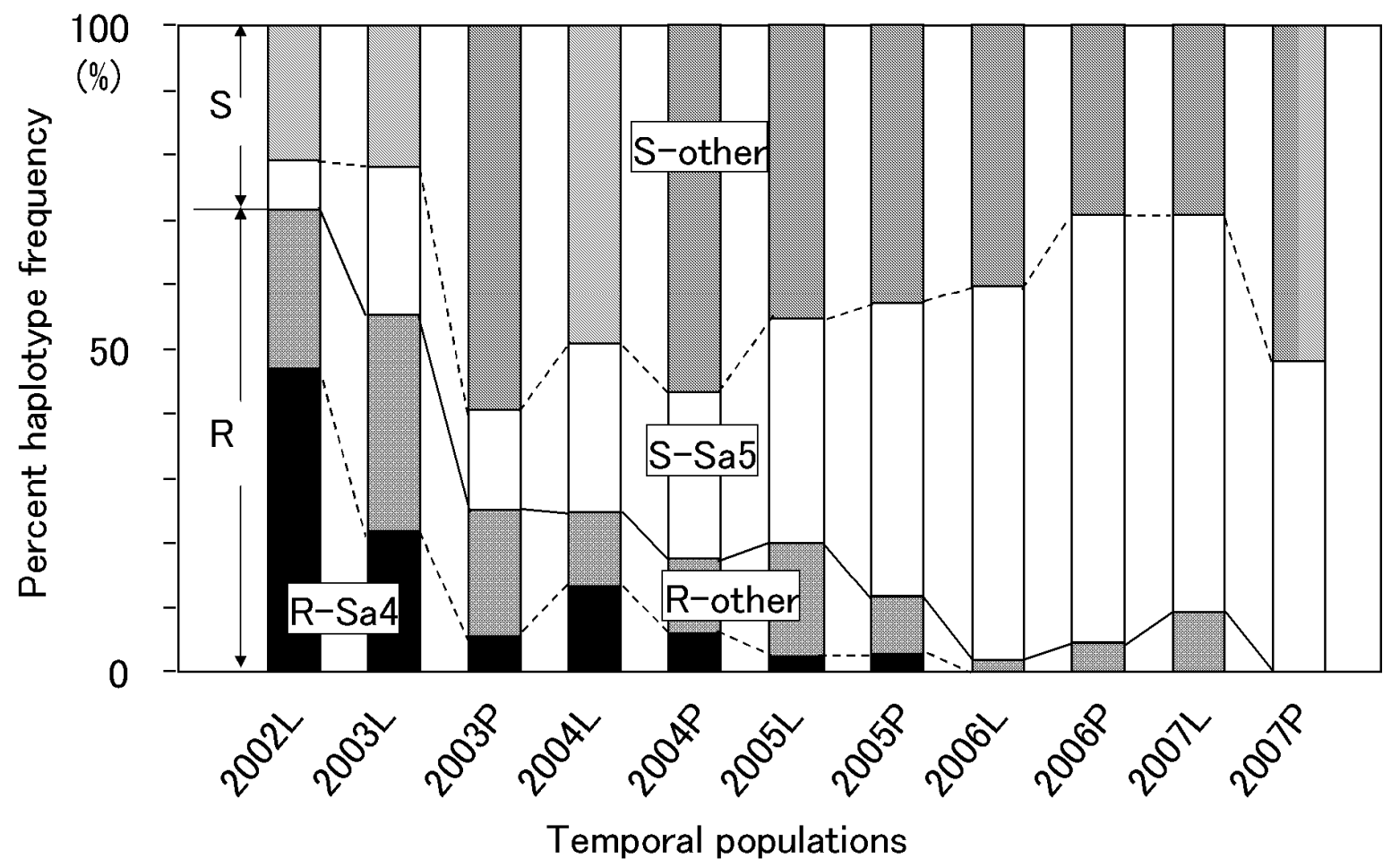

Fig. 3. Proportions of predominant haplotypes among resistant and sensitive isolates. R-Sa4 is the predominant haplotype among melanin biosynthesis inhibitor targeting scytalone dehydratase (MBI-D)-resistant isolates under fungicide application; S-Sa5 is the predominant haplotype among MBI-D-sensitive isolates after fungicide discontinuance. R-other indicates all haplotypes among resistant isolates except R-Sa4; S-other indicates all haplotypes among sensitive isolates except S-Sa5.

Table 2. Pairwise comparisons of genetic differentiation $\left(\mathrm{F}_{\mathrm{ST}}\right)$ in 11 temporal populations of Pyricularia oryzae in Saga Prefecture during 2002 to 2007 among sensitive isolates (above diagonal) and among total isolates (below diagonal) ${ }^{\mathrm{a}, \mathrm{b}}$

\begin{tabular}{|c|c|c|c|c|c|c|c|c|c|c|c|}
\hline Population & 2002-L & 2003-L & 2003-P & 2004-L & 2004-P & 2005-L & 2005-P & 2006-L & 2006-P & 2007-L & 2007-P \\
\hline $2002-\mathrm{L}$ & & $0.026 * *$ & $0.057 * *$ & $0.020 * *$ & $0.027 * *$ & $0.103 * *$ & $0.048 * *$ & $0.087 * *$ & $0.086 * *$ & $0.069 * *$ & $0.071 * *$ \\
\hline 2003-L & $0.065 * *$ & $\ldots$ & $0.064 * *$ & $0.016 * *$ & $0.032 * *$ & $0.145^{* *}$ & $0.038 * *$ & $0.034 * *$ & $0.024 * *$ & $0.019 * *$ & $0.015 * *$ \\
\hline 2003-P & $0.210^{* * *}$ & $0.066^{* *}$ & & $0.043 * *$ & $0.058 * *$ & $0.160 * *$ & $0.025^{* *}$ & $0.097 * *$ & $0.123 * *$ & $0.117 * *$ & $0.093 * *$ \\
\hline 2004-L & $0.167 * *$ & $0.033 * *$ & $0.023 * *$ & $\ldots$ & $0.011^{* *} *$ & $0.144 * *$ & $0.045^{* *}$ & $0.047 * *$ & $0.045^{* *}$ & $0.048 * *$ & $0.043^{* *}$ \\
\hline 2004-P & $0.225^{* *}$ & $0.072 * *$ & $0.034 * *$ & $0.012 * *$ & & $0.147 * *$ & $0.066^{* *}$ & $0.046^{* *}$ & $0.064 * *$ & $0.051 * *$ & $0.050 * *$ \\
\hline 2005-L & $0.325 * *$ & $0.180 * *$ & $0.121 * *$ & $0.115^{* *}$ & $0.103 * *$ & & $0.092 * *$ & $0.199 * *$ & $0.218 * *$ & $0.176^{* * *}$ & $0.181 * *$ \\
\hline 2005-P & $0.366^{* * *}$ & $0.183 * *$ & $0.073 * *$ & $0.085 * *$ & $0.065 * *$ & $0.062 * *$ & $\ldots$ & $0.069 * *$ & $0.079 * *$ & $0.077 * *$ & $0.054 * *$ \\
\hline 2006-L & $0.371 * *$ & $0.187 * *$ & $0.111 * *$ & $0.086 * *$ & $0.054 * *$ & $0.149 * *$ & $0.051 *$ & $\ldots$ & $0.016 * *$ & $0.018 * *$ & $0.013 * *$ \\
\hline 2006-P & $0.405^{* *}$ & $0.217 * *$ & $0.141 * *$ & $0.100 * *$ & $0.076^{* * *}$ & $0.151 * *$ & $0.044 * *$ & $0.017 *$ & & $0.006 \mathrm{~ns}$ & $0.011 * *$ \\
\hline 2007-L & $0.397 * *$ & $0.212 * *$ & $0.142 * *$ & $0.106^{* *}$ & $0.073 * *$ & $0.145^{* *}$ & $0.059 *$ & $0.014 *$ & $0.004 \mathrm{~ns}$ & & $<0.001 \mathrm{~ns}$ \\
\hline 2007-P & $0.396^{* *}$ & $0.208 * *$ & $0.125^{* *}$ & $0.101 * *$ & $0.070 * *$ & $0.144 * *$ & $0.040 *$ & $0.011 *$ & $0.011 * *$ & $0.002 \mathrm{~ns}$ & $\ldots$ \\
\hline
\end{tabular}

${ }^{\text {a }} \mathrm{L}=$ leaf blast, $\mathrm{P}=$ panicle blast. Index of genetic differentiation $\left(\mathrm{F}_{\mathrm{ST}}\right)$ was calculated to compare population pairs based on Pot 2 repetitive element polymerase chain reaction (rep-PCR) data.

b **Significant at $P<0.01$; *significant at $P<0.05$; and $\mathrm{ns}=$ not significant. 
fungicide conversion from MBI-D to other alternatives with distinct modes of action.

The frequency of the predominant haplotype among resistant isolates, $\mathrm{Sa} 4$, decreased rapidly after the discontinuance of MBI-D fungicides, indicating that $\mathrm{Sa} 4$ isolates cannot survive well in the absence of MBI-D selection pressure, although haplotypic diversities among resistant isolates remained high for the first 3 years. Instead, haplotype $\mathrm{Sa} 5$ in sensitive isolates became predominant. This conversion meant that $\mathrm{Sa} 4$ isolates had lower competitive ability than sensitive isolates in the absence of MBI-D pressure, suggesting that there was a fitness cost related to development of MBI-D resistance in the field. However, it is still unclear why Sa4 isolates were able to multiply predominantly and spread rapidly among resistant isolates. These results suggest that the ecological fitness of MBI-D-resistant strains may vary with fungicide pressure.

Reduced sensitivity to MBI-D is thought to be the result of a single mutation in SDH that occurs at low frequency or in naturally occurring subpopulations of resistant strains. The widespread use of MBI-D fungicides would wipe out the sensitive portion of the population, leaving only the resistant portion to survive, multiply, and become dominant. This shift toward resistance is rapid when single gene mutations confer resistance (15). In Saga,
MBI-D-resistant strains became dominant only 3 to 4 years after the introduction of the fungicides (28). Köller and Scheinpflug (14) have explained how resistance can develop in populations of fungal pathogens. After discontinuance of fungicides, the sensitive portion of the population will recover if the fitness of the resistant subpopulation is lower than that of the sensitive one in the absence of fungicide pressure. Our results agree with this model: all pairwise $\mathrm{F}_{\mathrm{ST}}$ values among subpopulations of sensitive isolates were relatively small and invariant during 2002 to 2007, although the proportions of both subpopulations changed dramatically. This prolonged stable structure of subpopulations can be explained by the fact that $P$. oryzae usually reproduces asexually by conidia. Significant linkage disequilibrium between simple sequence repeat (SSR) markers within Japanese isolates indicates that this is not a random mating population (29). These results are consistent with reports that $P$. oryzae populations have a relatively simple structure in Japan, with only a few distinct genetic groups $(3,25,27)$.

The frequency of resistance tended to decrease faster in panicle blast populations than in leaf blast populations. This means that the frequency of resistance was not appreciably influenced by bottleneck effects through storage at low temperature,

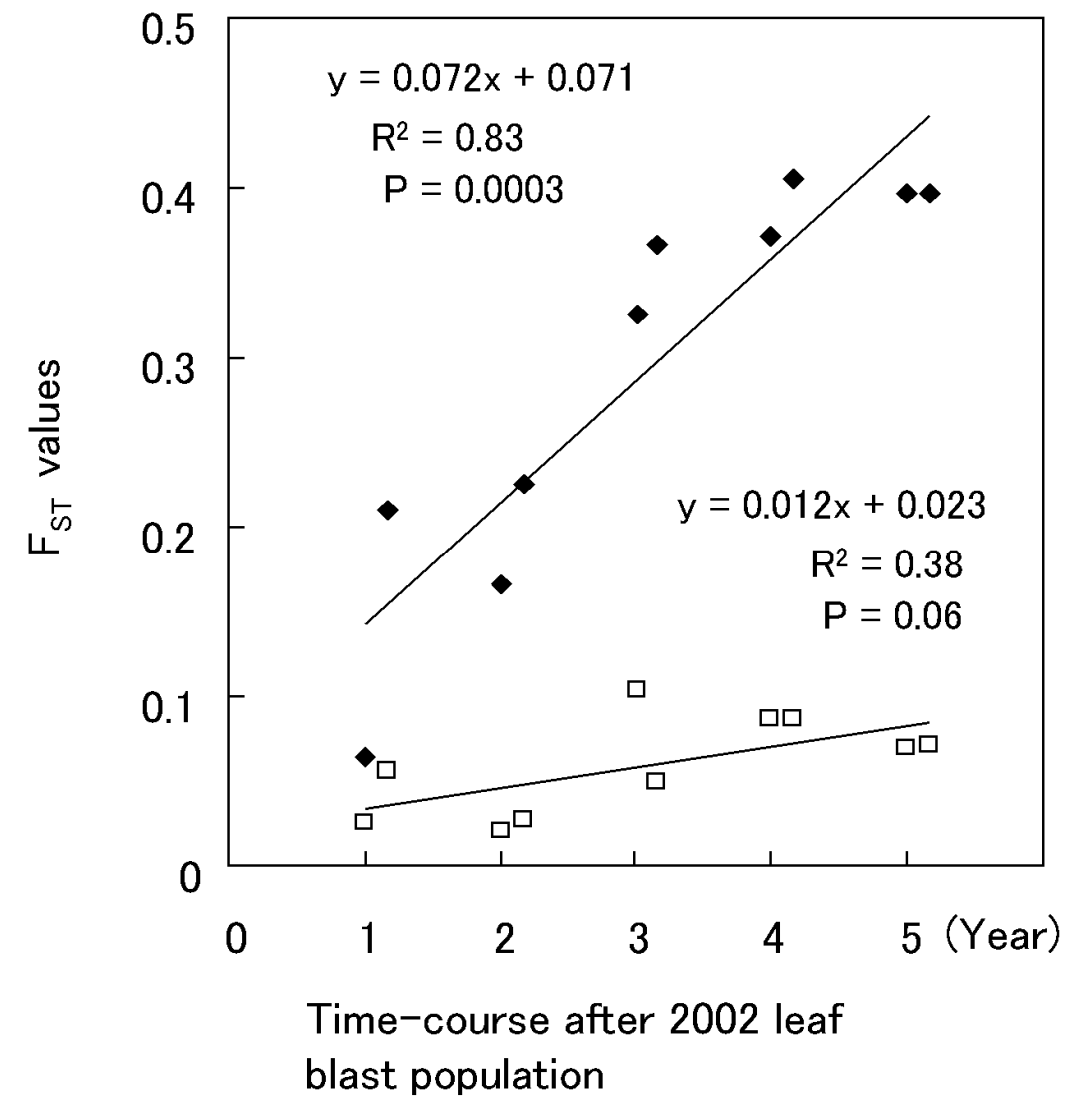

Fig. 4. Relationship between genetic distance ( $\mathrm{F}_{\mathrm{ST}}$ value) and time (years) between the 2002 leaf blast population and the other 10 temporal populations of Pyricularia oryzae in Saga Prefecture: solid diamond, pairwise comparisons with all isolates; open square, with sensitive isolates. seed sterilization, germination under anaerobic conditions, and growth of seedlings in nursery boxes. The rapid decrease in the frequency of resistance was additionally due to the active multiplication of wild-type $P$. oryzae, which multiplies exponentially by conidia through four to five life cycles per rice season. Therefore, even if the fitness cost is extremely small, wildtype strains may quickly swamp the resistant subpopulation through active multiplication and the asexual life cycle.

Our present results and previous findings suggest that the level of fitness cost imposed by resistance to MBI-D may be small. The proportion of fields infested with resistant fungus was high (over $70 \%$ ) when MBI-D fungicides were applied over only $20 \%$ of the cultivation area. This observation appears to be consistent with the simulations of low fitness cost using the metapopulation model devised by Parnell et al. (21). Also, MBI-D-resistant and -sensitive isolates of $P$. oryzae had similar fitness parameters such as growth rate, temperature sensitivity, UV tolerance, and pathogenicity $(13,26)$. The V75M variant of SDH still retained a significant level of enzymatic activity (33). In addition, haplotypic diversity among resistant isolates was retained at a relatively high level for the first 3 years after discontinuance of fungicides, suggesting the difficulty in separating the fitness cost from the differences in ecological fitness within the gene pool.

In conclusion, MBI-D resistance decreased in the absence of MBI-D fungicide pressure in the field. This reversion to MBI-D sensitivity may have important implications for the management of rice blast. Depending upon the degree of fitness cost and rapid changes in population structure, it may be possible to reintroduce MBI-D fungicides at regular intervals in areas where resistance has already developed. However, on the basis of several observations, it appears that the fitness cost associated with MBI-D resistance may be small. Therefore, it is unclear whether antiresistance strategies involving MBI-D application will depend on the degree of fitness cost. To delay MBI-D resistance and keep it under control, further practical studies of management strategy are necessary to assess the effects of fungicide rotation or combinations.

\section{ACKNOWLEDGMENTS}

We thank the numerous staff of the prefectural Agricultural Research Centers and Plant Protection Offices located in Saga for their help in the sampling of P. oryzae isolates.

\section{LITERATURE CITED}

1. Baraldi, E., Mari, M., Chierici, E., Pondrelli, M., Bertolini, P., and Pratella, G. C. 2003. Studies on thiabendazole resistance of Penicillium expansum of pears: Pathogenic fitness and genetic characterization. Plant Pathol. 52:362-370.

2. Couch, B. C., and Kohn, L. M. 2002. A multilocus gene genealogy concordant with host 
preference indicates segregation of a new species, Magnaporthe oryzae from M. grisea. Mycologia 94:683-693.

3. Don, L. D., Kusaba, M., Urashima, A. S., Tosa, Y., Nakayashiki, H., and Mayama, S. 1999. Population structure of the rice blast fungus in Japan examined by DNA fingerprinting. Ann. Phytopathol. Soc. Jpn. 65:15-24.

4. Fukaya, T. 1987. Declining of resistant strains of Pyricularia oryzae against IBP after breaking of isoprothiolane and organophosphorus fungicides. (In Japanese.) Ann. Phytopathol. Soc. Jpn. 53:400.

5. Fukaya, T., and Kobayashi, J. 1987. Occurrence of resistant strains of Pyricularia oryzae Cavara against kasugamycin in Akita prefecture and declining of the strains after breaking of chemical application. (In Japanese.) Ann. Rep. Plant Prot. North Jpn. 33:25-28.

6. Hsiang, T., and Chastagner, G. A. 1991. Growth and virulence of fungicide-resistant isolates of three species of Botrytis. Can. J. Plant Pathol. 13:226-231.

7. Ishi, H. 2006. Impact of fungicide resistance in plant pathogens on crop disease control and agricultural environment. JARQ 40:205-211.

8. Kachroo, P., Leong, S., and Chattoo, B. B. 1994. Pot 2, inverted repeat transposon from the rice blast fungus Magnaporthe grisea. Mol. Gen. Genet. 245:339-348.

9. Kaku, K., Takagaki, M., Shimizu, T., and Nagayama, K. 2003. Diagnosis of dehydratase inhibitors in melanin biosynthesis inhibitor (MBI-D) resistance by primer-introduced restriction enzyme analysis in scytalone dehydratase gene of Magnaporthe grisea. Pest Manag. Sci. 59:843-846.

10. Karaoglanidis, G. S., Thanassoulopoulos, C. C., and Ioannidis, P. M. 2001. Fitness of Cercospora beticola field isolates - resistant and - sensitive to demethylation inhibitor fungicides. Eur. J. Plant Pathol. 107:337-347.

11. Katagiri, M., Uesugi, Y., and Umehara, Y. 1980. Development of resistance to organophosphorus fungicides in Pyricularia oryzae in the field. J. Pestic. Sci. 5:417-421.

12. Kato, M., Mizubuti, E. S., Goodwin, S. B., and Fry, W. M. 1997. Sensitivity to protectant fungicides and pathogenic fitness of clonal lineages of Phytophthora infestans in the United States. Phytopathology 87:973-978.

13. Kimura, N. 2006. Comparison of biological properties of resistant field isolates of Magnaporthe grisea with susceptible isolates to melanin biosynthesis inhibitors targeting scyta- lone dehydratase (MBI-Ds). (In Japanese.) Abstr. Sympos. Res. Comm. Fungicide Resistance, 16th. 41-50.

14. Köller, W., and Scheinpflug, H. 1987. Fungal resistance to sterol biosynthesis inhibitors: A new challenge. Plant Dis. 71:1066-1074

15. Ma, Z., and Michailides, T. J. 2005. Advances in understanding molecular mechanisms of fungicide resistance and molecular detection of resistant genotypes in phytopathogenic fungi. Crop Prot. 24:853-863.

16. Matsuyama, N., and Yamaguchi, T. 1981. Alteration of virulence and aggressiveness during serial transfer and simplified storage of rice blast fungus Pyricularia oryzae Cav. Ann. Phytopathol. Soc. Jpn. 47:457-463.

17. McDonald, B. A. 1997. The population genetics of fungi: Tools and techniques. Phytopathology 87:448-453.

18. Miura, H., Ito, H., and Takahashi, S. 1975. Occurrence of resistant strains of Pyricularia oryzae to kasugamycin as a cause of the diminished fungicidal activity to rice blast. (In Japanese, with English summary.) Ann. Phytopathol. Jpn. 41:415-417.

19. Nakasako, M., Motoyama, T., Kurahashi, Y., and Yamaguchi, I. 1998. Cryogenic X-ray crystal structure analysis for the complex of scytalone dehydratase of a rice blast fungus and its tight-binding inhibitor, carpropamid: The structural basis of tight-binding inhibition. Biochemistry 37:9931-9939.

20. Nei, M. 1973. Analysis of gene diversity in subdivided populations. Proc. Natl. Acad. Sci. (USA) 70:3321-3323.

21. Parnell, S., van den Bosch, F., and Gilligan, C. A. 2006. Large-scale fungicide spray heterogeneity and the regional spread of resistant pathogen strains. Phytopathology 96:549-555.

22. Peever, T. L., and Milgroom, M. G. 1994. Lack of correlation between fitness and resistance to sterol biosynthesis-inhibiting fungicides in Pyrenophora teres. Phytopathology 84: 515519.

23. Sasaki, N., Arai, M., and Suzuki, F. 2006. RepPCR fingerprinting analysis of Pyricularia oryzae isolates with decreased sensitivity to dehydratase inhibitors in melanin biosynthesis (MBI-D) in Iwate prefecture and their pathogenic races. (In Japanese.) Annu. Rep. Plant Prot. North Jpn. 57:10-13

24. Sawada, H., Sugihara, M., Takagaki, M., and Nagayama, K. 2004. Monitoring and characterization of Magnaporthe grisea isolates with decreased sensitivity to scytalone dehydratase inhibitors. Pest Manag. Sci. 60:777-785.

25. Sone, T., Abe, T., Yoshida, N., Suto, M., and Tomita, F. 1997. DNA fingerprinting and electrophoretic karyotyping of Japanese isolates of rice blast fungus. Ann. Phytopathol. Soc. Jpn. 63:155-163.

26. Sugihara, M., and Takagaki, M. 2003. Resistance of Magnaporthe grisea to melanin biosynthesis inhibitors targeting scytalone dehydratase (MBI-D). 4. Biological properties of resistant isolates and general countermeasure against their predomination. (In Japanese.) Abstr. Sympos. Res. Comm. Fungicide Resistance, 13th. 59-68.

27. Suzuki, F., Arai, M., and Yamaguchi, J. 2006. DNA fingerprinting of Pyricularia grisea by rep-PCR using single primers designed from the terminal inverted repeat of each of the transposable elements Pot 2 and MGR586. J. Gen. Plant Pathol. 72:314-317.

28. Suzuki, F., Arai, M., and Yamaguchi, J. 2007. Genetic analysis of Pyricularia grisea population by rep-PCR during development of resistance to scytalone dehydratase inhibitors of melanin biosynthesis. Plant Dis. 91:176-184

29. Suzuki, F., Suga, H., Tomimura, K., Fuji, S Arai, M., Koba, A., and Nakajima, T. 2009. Development of simple sequence repeat markers for Japanese isolates of Magnaporthe grisea. Mol. Ecol. Res. 9:588-590.

30. Takagaki, M., Kaku, K., Watanabe, S., Kawai, K., Shimizu, T., Sawada, H., Kumakura, K. and Nagayama, K. 2004. Mechanism of resistance to carpropamid in Magnaporthe grisea. Pest Manag. Sci. 60:921-926.

31. Valent, B., and Chumley, F. G. 1994. Avirulence genes and mechanism of genetic instability in the rice blast fungus. Pages 111-134 in Rice Blast Disease. R. S. Zeigler, S. A. Leong, and P. S. Teng, eds. CABI, Wallingford, UK.

32. Weir, B. S., and Cockerham, C. C. 1984. Estimating F-statistics for the analysis of populations. Evolution 38:1358-1370.

33. Yamada, N., Motoyama, T., Nakasako, M. Kagabu, S., Kudo, T., and Yamaguchi, I. 2004 Enzymatic characterization of scytalone dehydratase Val75Met variant found in melanin biosynthesis dehydratase inhibitor (MBI-D) resistant strains of the rice blast fungus. Biosci. Biotechnol. Biochem. 68:615-621.

34. Yamaguchi, J., Kuchiki, F., Hirayae, K., and So, K. 2002. Decreased effect of carpropamid for rice blast control in the west north area of Saga Prefecture in 2001. (In Japanese.) Jpn. J. Phytopathol. 68:261. 